\title{
Pengaruh Kualitas layanan Terhadap Kepuasan Mahasiswa dengan Moderasi Budaya Organisasi dan Reputasi
}

\author{
Nilda Tri Putri, Budi Satria, Elita Amrina, dan Alfadhlani \\ Fakultas Teknik, Jurusan Teknik Industri, Universitas Andalas \\ Limau Manih, Padang 25175 \\ Email: nildatp@eng.unand.ac.id, budi.d.satria@gmail.com, elita@eng.unand.ac.id, alfadhlani@eng.unand.ac.id
}

\begin{abstract}
The purpose of this paper is to study the effects of service quality, organization culture and reputation on student satisfaction. This study uses 397 data collected from undergraduate students of Andalas University. The data is analyzed using structural equation modeling with SmartPLS 3.0, because of its ability to evaluate the measurement as well as the structural model. The results of this study show that service quality, organization culture and reputation significantly affect the student satisfaction. It is also found that service quality has the highest effect on student satisfaction, which means that increasing Andalas University service quality would significantly improve the satisfaction of its students. The results of this study also show that the organization culture nor reputation do not have moderating effect on the relationship between service quality and student satisfaction. This finding implies that organization culture nor reputation would not strengthen nor weaken the relationship between service quality and student satisfaction. Based on the findings, this study proposes several recommendations for University of Andalas to improve the satisfaction of its students.
\end{abstract}

Keywords: service quality, organization culture, reputation, student satisfaction

\begin{abstract}
Abstrak
Penelitian ini bertujuan untuk menganalisis pengaruh kualitas layanan, budaya organisasi, dan reputasi terhadap kepuasan mahasiswa Universitas Andalas. Penelitian ini dilakukan dengan cara menyebar kuesioner kepada mahasiswa S1 yang berjumlah 397 mahasiswa. Metode yang digunakan pada penelitian ini adalah structural equation modelling (SEM) yang dibantu dengan aplikasi SMARTPLS 3.0. Metode ini dipilih karena metode ini dapat menguji hubungan antar variabel yang ada pada sebuah model, baik itu hubungan antara variabel dengan konstruknya maupun hubungan antar konstruk. Hasil penelitian menunjukkan bahwa kualitas layanan, budaya organisasi, dan reputasi memiliki pengaruh yang signifikan terhadap kepuasan mahasiswa, artinya ketiga variabel tersebut akan mempengaruhi tingkat kepuasan mahasiswa. Variabel yang paling berpengaruh signifikan terhadap kepuasan mahasiswa adalah variabel kualitas layanan. Berdasarkan hal tersebut dengan meningkatkan kualitas layanan Universitas Andalas dapat mempengaruhi tingkat kepuasan mahasiswa secara signifikan. Selain itu, budaya organisasi dan reputasi sebagai variabel moderasi antara kualitas pelayan terhadap kepuasan mahasiswa juga diteliti pada penelitian ini, namun hasil yang didapatkan yaitu tidak memiliki pengaruh yang signifikan. Hal ini berarti bahwa budaya organisasi dan reputasi tidak memperkuat atau memperlemah hubungan antara kualitas layanan terhadap kepuasan mahasiswa. Rekomendasi perbaikan diberikan berdasarkan variabel yang berpengaruh signifikan dengan tujuan meningkatkan kepuasan mahasiswa Universitas Andalas.
\end{abstract}

Kata Kunci: kualitas layanan, budaya organisasi, reputasi, kepuasan mahasiswa 


\section{Pendahuluan}

Perkembangan dunia pendidikan yang saat ini semakin pesat, membuat pemerintah terus menerus melakukan perbaikan sistem pendidikan. Hal ini sejalan dengan meningkatnya kesadaran masyarakat Indonesia terhadap pentingnya menempuh dunia pendidikan. Widodo (2016) menyatakan bahwa terdapat beberapa factor penyebab rendahnya kualitas pendidikan di Indonesia seperti: rendahnya sarana fisik, kualitas pengajar yang masih belum baik, rendahnya prestasi siswa dan mahalnya biaya pendidikan. Berdasarkan hal tersebut, perguruan tinggi negeri maupun swasta harus membantu program pemerintah dalam melakukan perbaikan sistem pendidikan tersebut. Perbaikan ini ditujukan untuk memenuhi kebutuhan dan keinginan konsumen perguruan tinggi, yaitu salah satunya mahasiswa.

Universitas Andalas (UNAND) sebagai universitas tertua di luar pulau jawa, memiliki 15 fakultas yang telah terakreditasi $A$ dan termasuk dalam peringkat sepuluh besar kampus terbaik di Indonesia pada tahun 2018. Namun pencapaian tersebut masih belum optimal dirasakan oleh mahasiswa sebagai konsumen internal terutama dalam hal kualitas layanan yang diberikan oleh UNAND. Survei awal telah dilakukan terhadap 128 mahasiswa, didapatkan hasil bahwa keluhan yang paling banyak dirasakan mahasiswa yaitu terkait fasilitas fisik yang ada, sikap staf atau tenaga kependidikan (tendik), respon staf atau tendik terhadap keluhan mahasiswa, ketepatan waktu dan keakuratan pelayanan. Berdasarkan hasil kuesioner tersebut dapat disimpulkan bahwa dari 128 responden, 96\% responden menyatakan bahwa masih belum puas dengan kualitas layanan Universitas Andalas.

Kepuasan mahasiswa dapat ditingkatkan dengan mengidentifikasi faktor faktor yang mempengaruhinya agar suatu perguruan tinggi dapat memperbaiki sistemnya dalam meningkatkan kepuasan mahasiswa. Penelitian-penelitian terdahulu menjelaskan bahwa kepuasan mahasiswa dipengaruhi oleh beberapa hal diantaranya adalah kualitas pelayanan yang diberikan oleh penyedia jasa layanan. Kualitas suatu lembaga perguruan tinggi menjadi salah satu faktor penting dalam keberhasilan perguruan tinggi (Kitchroen, 2004). Kepuasan mahasiswa tidak hanya dipengaruhi oleh kualitas layanan, budaya organisasi juga mempengaruhi hal tersebut. AlOtaib et al. (2019) menjelaskan bahwa terdapat empat budaya organisasi yang akan mempengaruhi kepuasan mahasiswa, yaitu kerja sama tim (team work), kesesuaian (compatibility), misi (mission) dan kemampuan beradaptasi (adaptability).

Selain kualitas layanan pendidikan dan budaya, Khattab (2018) dalam penelitiannya menjelaskan bahwa kualitas layanan dalam sektor pendidikan perlu mempertimbangkan faktor citra atau reputasi kampus. Khattab (2018) menyimpulkan bahwa kepuasan mahasiswa akan berdampak terhadap reputasi perguruan tinggi. Reputasi perguruan tinggi yang baik akan mempengaruhi persepsi masyarakat dalam menentukan layanan pendidikan yang akan mereka pilih. Apabila perguruan tinggi tersebut memiliki reputasi yang baik, maka masyarakat akan bersedia mengeluarkan biaya yang lebih atas biaya studi pada perguruan tinggi yang bereputasi baik tersebut. Berdasarkan kuesioner awal dapat dilihat bahwa kualitas layanan Universitas Andalas belum baik sehingga mempengaruhi tingkat kepuasan mahasiswa. Penelitian terdahulu juga menyatakan bahwa kepuasan mahasiswa juga dipengaruhi oleh variabel lain seperti budaya organisasi dan reputasi kampus. Uluputty (2019) berpendapat bahwa kepuasan mahasiswa sangat dipengaruhi oleh kualitas layanan, budaya akademik, dan kinerja dosen. Wibowo (2009) juga berpendapat bahwa kualitas layanan dan reputasi perguruan tinggi berpengaruh terhadap kepuasaan mahasiswa.

Penelitian yang berkaitan dengan analisis hubungan antara kualitas layanan, budaya organisasi, dan reputasi terhadap kepuasan mahasiswa belum pernah dilakukan di Universitas Andalas. Safitri (2010) hanya melakukan penelitian yang berfokus pada fakultas teknik, dan penelitian Kamal (2016) hanya menggunakan variabel kualitas layanan.

Berdasarkan hal tersebut, untuk membantu Universitas Andalas dalam meningkatkan kepuasan mahasiswa dan belum adanya penelitian terkait di Universitas Andalas, maka penelitian ini bertujuan untuk menganalisis pengaruh hubungan ketiga faktor yaitu kualitas layanan, budaya organisasi, dan reputasi terhadap kepuasan mahasiswa. 


\section{Tinjauan Pustaka}

\section{Kualitas layanan}

Secara umum pengertian kualitas telah didefinisikan oleh llyas (2011) dalam Martasubrata \& Suwatno (2016) bahwa kualitas merupakan karakteristik yang dimiliki oleh produk berupa barang atau jasa yang mampu memuaskan kebutuhan dan keinginan pelanggan baik yang ditentukan ataupun yang tersirat. Kualitas layanan merupakan kegiatan berwujud atau tidak berwujud yang dilakukan dengan tujuan untuk memberikan kepuasan terhadap pengguna layanan [(Dharmesta, 1999 dalam Yuliana, 2012); (Parasuraman, 1988 dalam Ximenes, 2017)]. Zeithaml (2009) dalam Apriyani \& Sunarti (2017) mengklasifikasikan kualitas layanan sebagai fokus penilaian yang mencerminkan persepsi konsumen ke dalam lima dimensi servqual yang terdiri dari keandalan (Reliability), daya tanggap (Responsiveness), Jaminan (Assurance), empati (Empathy), dan bukti fisik (Tangible).

\section{Budaya Organisasi}

Alghamdi (2013) dan Schermerhorn et al., (2002) dalam Saadi (2017) menjelaskan bahwa budaya organisasi adalah sekumpulan norma, nilai-nilai, keyakinan, asumsi, dan sikap bersama dari anggota organisasi yang berpengaruh terhadap perilaku, hasil kinerja, dan lingkungan eksternal organisasi dan menjadi panduan perilaku anggotanya.

Budaya organisasi memiliki hubungan timbal balik dengan kualitas suatu perusahaan. Argumen ini diperkuat berdasarkan penelitian Lukasova (2004) dalam Jancikova \& Brychta (2009) yang menyatakan bahwa antara Total Quality Management dan Budaya organisasi merupakan dua hal yang saling terkait.

\section{Reputasi}

Kualitas layanan dan kepuasan pelanggan sangat berhubungan dengan reputasi. Hal ini sesuai dengan penelitian Zeithaml (1988) dalam Aryska \& Kasmirudin (2017) yang menyatakan bahwa kualitas layanan produk berupa barang maupun jasa sangat berhubungan erat dengan reputasi atau merek (brand) dari produk tersebut.

Fombrum (1996) dalam Aryska \& Kasmirudin (2017) mendefinisikan reputasi sebagai gambaran menyeluruh dari kegiatan suatu organisasi atau perusahaan pada masa lampau dan prospek organisasi tersebut di masa datang dibandingkan dengan pesaingnya melalui kebijakan yang diambil.

\section{Kepuasan Mahasiswa}

Oliver (1993) dalam Rinala et al. (2013) mengatakan bahwa kepuasan pelanggan merupakan perspektif yang dirasakan oleh konsumen setelah menggunakan produk barang atau jasa yang diberikan oleh suatu organisasi atau perusahaan. Kotler (2006) dalam Aryska \& Kasmirudin (2017) dan Satriyanti (2012) juga mendefinisikan kepuasan pelanggan sebagai perbandingan antara perspektif pelanggan terhadap apa yang dirasakannya dari produk atau jasa dengan apa yang diharapkannya.

Jadi berdasarkan pengertian yang telah dipaparkan oleh para ahli, maka kepuasan pelanggan dapat disimpulkan sebagai hasil yang dirasakan oleh pelanggan setelah merasakan atau menggunakan produk atau jasa sama atau melebihi harapan dari kebutuhan dan keinginan pelanggan.

\section{Penelitian Terdahulu}

Penelitian tentang kepuasan mahasiswa telah dilakukan oleh beberapa peneliti sebelumnya seperti disajikan pada Tabel 1 .

Tabel 1. Penelitian terdahulu

\begin{tabular}{|c|c|l|}
\hline Peneliti & Metode & \multicolumn{1}{|c|}{ Hasil Penelitian } \\
\hline $\begin{array}{c}\text { Khattab } \\
(2018)\end{array}$ & IPA & $\begin{array}{l}\text { Reputasi perguruan tinggi } \\
\text { menentukan kepuasan } \\
\text { mahasiswa. }\end{array}$ \\
\hline $\begin{array}{c}\text { Al-Otaib } \\
\text { et al. } \\
(2019)\end{array}$ & $\begin{array}{c}\text { Structural } \\
\text { Equation } \\
\text { Modelling } \\
\text { (SEM) }\end{array}$ & $\begin{array}{l}\text { Terdapat empat budaya } \\
\text { organisasi yang berpengaruh } \\
\text { terhadap kepuasan mahasiswa } \\
\text { yaitu team work, compability, } \\
\text { mission \& adaptability. }\end{array}$ \\
\hline $\begin{array}{c}\text { Kamal } \\
(2016)\end{array}$ & $\begin{array}{c}\text { GAP 5 } \\
\text { dan CSI } \\
\text { Index }\end{array}$ & $\begin{array}{l}\text { Dimensi prioritas untuk } \\
\text { perbaikan kualitas layanan } \\
\text { Universitas Andalas adalah } \\
\text { dimensi reliability. }\end{array}$ \\
\hline $\begin{array}{c}\text { Safitri } \\
(2015)\end{array}$ & $\begin{array}{c}\text { Structural } \\
\text { Equation } \\
\text { Modelling } \\
\text { (SEM) }\end{array}$ & $\begin{array}{l}\text { Dimensi yang paling } \\
\text { berpengaruh di Jurusan Teknik } \\
\text { Mesin adalah pelayanan non } \\
\text { akademik, sedang di Jurusan } \\
\text { Teknik Industri adalah } \\
\text { pelayanan administrasi. } \\
\text { Kepuasan mahasiswa } \\
\text { berpengaruh signifikan terhadap } \\
\text { loyalitas mahasiswa. }\end{array}$ \\
\hline $\begin{array}{c}\text { Wibowo } \\
(2009)\end{array}$ & $\begin{array}{c}\text { Analisis } \\
\text { regresi } \\
\text { linear } \\
\text { berganda }\end{array}$ & $\begin{array}{l}\text { Kualitas layanan dan reputasi } \\
\text { mempengaruhi nilai layanan, } \\
\text { namun kualitas layanan tidak } \\
\text { mempengaruhi kepuasan } \\
\text { mahasiswa. }\end{array}$ \\
\hline
\end{tabular}


Penelitian sebelumnya hanya menggunakan satu atau dua variabel untuk mengukur tingkat kepuasan mahasiswa dan populasi untuk penelitian biasanya hanya terbatas pada satu program studi atau satu fakultas.

\section{Metodologi}

\section{Populasi dan Sampel}

Mahasiswa aktif S1 UNAND menjadi populasi pada penelitian ini yang berjumlah 29.686 mahasiswa, yang terdiri dari 15 fakultas. Penelitian ini menggunakan metode Slovin untuk penarikan sampel dan diperoleh minimal sampel sebesar 395. Tabel 2 menunjukkan minimal sampel untuk setiap fakultas.

\section{Model Penelitian}

Penelitian ini menguji pengaruh langsung antara ketiga variabel terhadap kepuasan mahasiswa. Ketiga variabel tersebut adalah kualitas pelayanan, budaya organisasi, dan reputasi. Gambar 1 memperlihatkan model yang digunakan pada penelitian ini. Selain itu, penelitian ini juga menganalisis hubungan antara variabel budaya organisasi dan reputasi sebagai variabel moderasi antara kualitas layanan terhadap kepuasan mahasiswa seperti yang terlihat pada Gambar 2.

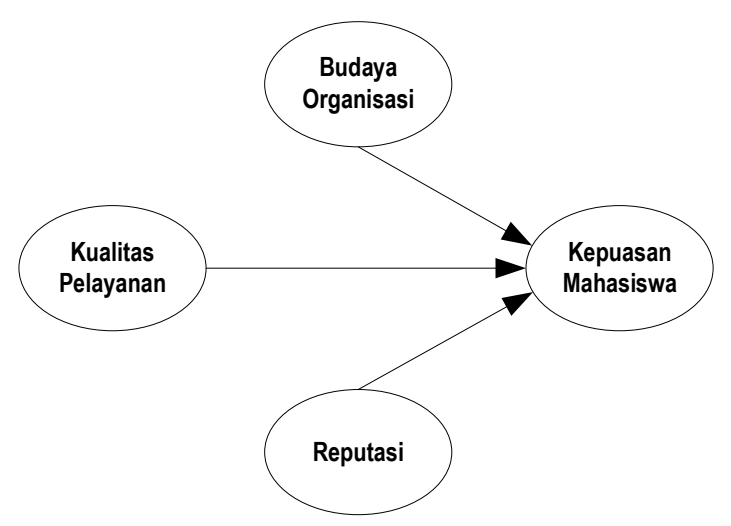

Gambar 1. Model penelitian

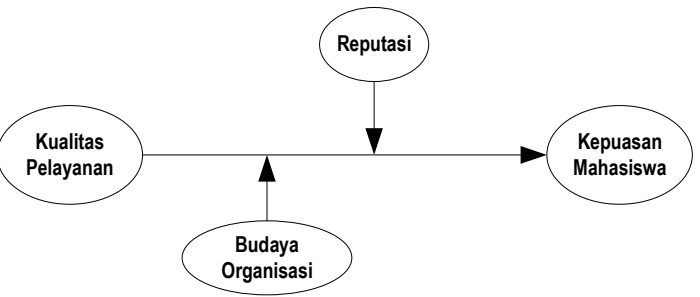

Gambar 2. Pengaruh moderasi dalam model penelitian
Tabel 2. Minimal sampel setiap fakultas

\begin{tabular}{|c|c|c|c|c|}
\hline No & Fakultas & $\begin{array}{c}\text { Jumlah } \\
\text { Mahasiswa } \\
\text { Aktif }\end{array}$ & Proporsi & Sampel \\
\hline 1 & $\begin{array}{l}\text { Fakultas } \\
\text { Pertanian }\end{array}$ & 2780 & $9 \%$ & 37 \\
\hline 2 & $\begin{array}{l}\text { Fakultas } \\
\text { Kedokteran }\end{array}$ & 3243 & $11 \%$ & 43 \\
\hline 3 & \begin{tabular}{|l|} 
Fakultas \\
Matematika \\
dan IImu \\
Pengetahuan \\
Alam
\end{tabular} & 2040 & $7 \%$ & 27 \\
\hline 4 & $\begin{array}{l}\text { Fakultas } \\
\text { Peternakan }\end{array}$ & 2033 & $7 \%$ & 27 \\
\hline 5 & $\begin{array}{l}\text { Fakultas } \\
\text { Teknik }\end{array}$ & 3425 & $12 \%$ & 46 \\
\hline 6 & $\begin{array}{l}\text { Fakultas } \\
\text { Teknologi } \\
\text { Pertanian }\end{array}$ & 1170 & $4 \%$ & 16 \\
\hline 7 & $\begin{array}{l}\text { Fakultas } \\
\text { Farmasi }\end{array}$ & 856 & $3 \%$ & 11 \\
\hline 8 & $\begin{array}{l}\text { Fakultas } \\
\text { Teknologi } \\
\text { Informasi }\end{array}$ & 622 & $2 \%$ & 8 \\
\hline 9 & \begin{tabular}{|l|} 
Fakultas \\
Keperawatan
\end{tabular} & 795 & $3 \%$ & 11 \\
\hline 10 & $\begin{array}{l}\text { Fakultas } \\
\text { Kesehatan } \\
\text { Masyarakat }\end{array}$ & 964 & $3 \%$ & 13 \\
\hline 11 & $\begin{array}{l}\text { Fakultas } \\
\text { Kedokteran } \\
\text { Gigi }\end{array}$ & 505 & $2 \%$ & 7 \\
\hline 12 & $\begin{array}{l}\text { Fakultas } \\
\text { Hukum }\end{array}$ & 2623 & $9 \%$ & 35 \\
\hline 13 & $\begin{array}{l}\text { Fakultas } \\
\text { Ekonomi }\end{array}$ & 4143 & $14 \%$ & 55 \\
\hline 14 & $\begin{array}{l}\text { Fakultas IImu } \\
\text { Budaya }\end{array}$ & 1971 & $7 \%$ & 26 \\
\hline 15 & $\begin{array}{l}\text { Fakultas IImu } \\
\text { Sosial dan } \\
\text { Politik }\end{array}$ & 2516 & $8 \%$ & 33 \\
\hline & Total & 29686 & $100 \%$ & 395 \\
\hline
\end{tabular}

\section{Hipotesis Penelitian}

Terdapat lima hipotesis pada penelitian ini yaitu:

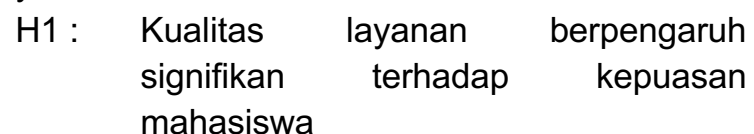

$\mathrm{H} 2$ : Budaya organisasi berpengaruh signifikan terhadap kepuasan mahasiswa

H3 : Reputasi berpengaruh signifikan terhadap kepuasan mahasiswa

$\mathrm{H} 4$ : Budaya organisasi berpengaruh signifikan sebagai moderasi antara kualitas layanan terhadap kepuasan mahasiswa 
H5 : Reputasi berpengaruh signifikan sebagai moderasi antara kualitas layanan terhadap kepuasan mahasiswa

\section{Metode Penelitian}

Penelitian ini menggunakan pemodelan persamaan structural atau dikenal dengan Structural Equation Modeling (SEM) dengan software SmartPLS 3.0. metode SEM digunakan untuk menganalisis hubungan antar variabel pada model penelitian ini yaitu hubungan antara variabel dengan konstruk dan hubungan antar konstruk. Terdapat beberapa alasan menggunakan metode SEM dibandingkan metode analisis data lainnya, yaitu:

1. Asumsinya lebih fleksibel.

2. SEM mampu mengatasi masalah ketidaknormalan data.

3. Tidak ada minimum sampel untuk penggunaan metode ini.

\section{Operasionalisasi Variabel}

Empat variabel yang dianalisis pada penelitian ini adalah kualitas pelayanan, budaya organisasi, dan reputasi. Indikator-indikator dari keempat variabel diambil dan dikembangkan dari beberapa jurnal.

Dimensi Servqual yang dijadikan sebagai variabel kualitas pelayanan pada penelitian ini adalah tangible, keandalan (reliability), daya tanggap (responsiveness), jaminan (assurance), dan empati. Tabel 3 hingga Tabel 7 memperlihatkan indikator dan kode indikator untuk kelima dimensi kualitas playanan.

Tabel 3. Indikator dimensi Tangible

\begin{tabular}{|l|c|}
\hline \multicolumn{1}{|c|}{ Indikator } & Kode \\
\hline $\begin{array}{l}\text { UNAND memiliki perpustakaan yang } \\
\text { lengkap }\end{array}$ & $\mathrm{X} .1 .1$ \\
\hline $\begin{array}{l}\text { Koleksi buku perpustakaan UNAND } \\
\text { memadai untuk kebutuhan mahasiswa }\end{array}$ & $\mathrm{X} .1 .2$ \\
\hline $\begin{array}{l}\text { Tersedianya kursi dan meja yang cukup } \\
\text { bagi mahasiswa di ruang baca } \\
\text { perpustakaan UNAND }\end{array}$ & $\mathrm{X} .1 .3$ \\
\hline $\begin{array}{l}\text { Ruang baca perpustakaan UNAND } \\
\text { dilengkapi AC/kipas angin }\end{array}$ & $\mathrm{X} .1 .4$ \\
\hline $\begin{array}{l}\text { Pencahayaan yang cukup di ruang baca } \\
\text { perpustakaan UNAND }\end{array}$ & $\mathrm{X} .1 .5$ \\
\hline $\begin{array}{l}\text { tersedianya fasilitas internet seperti } \\
\text { hotspot / wifi untuk mahasiswa }\end{array}$ & $\mathrm{X} .1 .6$ \\
\hline $\begin{array}{l}\text { Fasilitas ibadah yang terdapat di } \\
\text { lingkungan kampus bersih }\end{array}$ & $\mathrm{X} .1 .7$ \\
\hline $\begin{array}{l}\text { Tersedianya kipas angin atau AC di } \\
\text { mushalla atau masjid sehingga membuat } \\
\text { nyaman dalam melakukan ibadah }\end{array}$ & $\mathrm{X} .1 .8$ \\
\hline $\begin{array}{l}\text { Tempat berwudu di fasilitas ibadah } \\
\text { UNAND bersih }\end{array}$ & $\mathrm{X} .1 .9$ \\
\hline
\end{tabular}

\begin{tabular}{|c|c|}
\hline Indikator & Kode \\
\hline Lingkungan kampus yang selalu bersih & $\mathrm{X} .1 .10$ \\
\hline $\begin{array}{l}\text { Fasilitas parkir yang ada di UNAND } \\
\text { memadai untuk mahasiswa }\end{array}$ & $X .1 .11$ \\
\hline $\begin{array}{l}\text { Tersedianya kantin di lingkungan } \\
\text { kampus untuk memenuhi kebutuhan } \\
\text { mahasiswa }\end{array}$ & X.1.12 \\
\hline $\begin{array}{l}\text { Tersedianya tempat fotokopi di } \\
\text { lingkungan kampus untuk memenuhi } \\
\text { kebutuhan mahasiswa }\end{array}$ & X.1.13 \\
\hline $\begin{array}{l}\text { Fasilitas transportasi (Bus Kampus) yang } \\
\text { memadai disediakan oleh kampus }\end{array}$ & X.1.14 \\
\hline $\begin{array}{l}\text { Tersedianya AC/kipas angin di ruang } \\
\text { kuliah }\end{array}$ & X.1.15 \\
\hline $\begin{array}{l}\text { Fasilitas pembelajaran yang lengkap di } \\
\text { ruang kuliah }\end{array}$ & X.1.16 \\
\hline $\begin{array}{l}\text { Pencahayaan yang bagus di ruang } \\
\text { kuliah UNAND }\end{array}$ & X.1.17 \\
\hline Ruang kuliah yang ada di UNAND bersih & $\mathrm{X} .1 .18$ \\
\hline $\begin{array}{l}\text { Tersedianya peralatan keselamatan } \\
\text { seperti APAR di laboratorium UNAND }\end{array}$ & X.1.19 \\
\hline $\begin{array}{l}\text { Fasilitas laboratorium yang ada di } \\
\text { UNAND lengkap }\end{array}$ & $X .1 .20$ \\
\hline $\begin{array}{l}\text { Laboratorium yang ada di UNAND } \\
\text { relevan terhadap ilmu yang dibutuhkan } \\
\text { mahasiswa }\end{array}$ & X.1.21 \\
\hline $\begin{array}{l}\text { Tersedianya fasilitas untuk berdiskusi } \\
\text { (Gazebo, ruang diskusi, dll) bagi } \\
\text { mahasiswa di lingkungan UNAND }\end{array}$ & $X .1 .22$ \\
\hline $\begin{array}{l}\text { Dosen selalu berpakaian rapi di } \\
\text { lingkungan UNAND }\end{array}$ & X.1.23 \\
\hline $\begin{array}{l}\text { Tenaga kependidikan selalu berpakaian } \\
\text { rapi di lingkungan UNAND }\end{array}$ & X.1.24 \\
\hline UNAND memiliki Asrama yang bersih & $\mathrm{X} .1 .25$ \\
\hline Fasilitas asrama UNAND layak pakai & $\mathrm{X} .1 .26$ \\
\hline $\begin{array}{l}\text { Listrik di lingkungan asrama UNAND } \\
\text { jarang mati }\end{array}$ & X.1.27 \\
\hline $\begin{array}{l}\text { Kebutuhan air (mandi/masak) untuk } \\
\text { mahasiswa asrama terpenuhi }\end{array}$ & X.1.28 \\
\hline $\begin{array}{l}\text { UNAND menyediakan bantuan fasilitas } \\
\text { pembelajaran bagi mahasiswa apabila } \\
\text { terjadi bencana, musibah atau pandemi }\end{array}$ & X.1.29 \\
\hline
\end{tabular}

Tabel 4. Indikator dimensi Reliability

\begin{tabular}{|l|c|}
\hline \multicolumn{1}{|c|}{ Indikator } & Kode \\
\hline $\begin{array}{l}\text { Materi yang disampaikan dosen saat } \\
\text { perkuliahan dapat dipahami dengan baik } \\
\text { oleh mahasiswa }\end{array}$ & X.2.1 \\
\hline $\begin{array}{l}\text { dosen menyediakan waktu tanya jawab / } \\
\text { diskusi saat perkuliahan }\end{array}$ & $\mathrm{X} .2 .2$ \\
\hline $\begin{array}{l}\text { Tidak ada sikap diskriminasi dari dosen } \\
\text { terhadap mahasiswa }\end{array}$ & $\mathrm{X} .2 .3$ \\
\hline $\begin{array}{l}\text { Tidak ada sikap diskriminasi dari tenaga } \\
\text { kependidikan terhadap mahasiswa }\end{array}$ & $\mathrm{X} .2 .4$ \\
\hline $\begin{array}{l}\text { Jadwal kuliah disusun dengan baik (tidak } \\
\text { ada jadwal yang bentrok) }\end{array}$ & $\mathrm{X} .2 .5$ \\
\hline $\begin{array}{l}\text { Jadwal ujian disusun dengan baik (tidak } \\
\text { ada jadwal yang bentrok) }\end{array}$ & $\mathrm{X} .2 .6$ \\
\hline $\begin{array}{l}\text { UNAND sering mengadakan kuliah } \\
\text { lapangan atau kunjungan industri untuk } \\
\text { meningkatkan pembelajaran }\end{array}$ & $\mathrm{X} .2 .9$ \\
\hline Dosen datang tepat waktu & $\mathrm{X} .2 .10$ \\
\hline $\begin{array}{l}\text { Tenaga Kependidikan datang tepat } \\
\text { waktu }\end{array}$ & $\mathrm{X} .2 .11$ \\
\hline
\end{tabular}


Tabel 5. Indikator dimensi Responsiveness

\begin{tabular}{|l|l|}
\hline \multicolumn{1}{|c|}{ Indikator } & Kode \\
\hline $\begin{array}{l}\text { Tenaga kependidikan tanggap dalam } \\
\text { memberikan pelayanan kepada } \\
\text { mahasiswa }\end{array}$ & X.3.1 \\
\hline $\begin{array}{l}\text { Tenaga kependidikan cepat dalam } \\
\text { memberikan pelayanan kepada } \\
\text { mahasiswa }\end{array}$ & X.3.2 \\
\hline $\begin{array}{l}\text { Ketepatan tenaga kependidikan dalam } \\
\text { menanggapi keluhan mahasiswa }\end{array}$ & X.3.3 \\
\hline $\begin{array}{l}\text { Keluhan mahasiswa diselesaikan } \\
\text { dengan baik }\end{array}$ & X.3.4 \\
\hline $\begin{array}{l}\text { UNAND Menyediakan waktu bagi orang } \\
\text { tua mahasiswa untuk berkonsultasi }\end{array}$ & X.3.5 \\
\hline $\begin{array}{l}\text { Kejelasan informasi yang diberikan oleh } \\
\text { pegawai atau tenaga kependidikan }\end{array}$ & X.3.6 \\
\hline
\end{tabular}

Tabel 6. Indikator dimensi Assurance

\begin{tabular}{|c|c|}
\hline Indikator & Kode \\
\hline $\begin{array}{l}\text { Kemudahan mahasiswa dalam } \\
\text { mengakses nilai }\end{array}$ & $X .4 .1$ \\
\hline $\begin{array}{l}\text { Kemudahan mahasiswa dalam } \\
\text { mengakses jadwal kuliah }\end{array}$ & X.4.2 \\
\hline $\begin{array}{l}\text { Kemudahan mahasiswa dalam } \\
\text { mengakses jadwal ujian }\end{array}$ & $X .4 .3$ \\
\hline $\begin{array}{l}\text { keamanan di lingkungan kampus pada } \\
\text { siang hari terjaga dengan baik }\end{array}$ & $X .4 .4$ \\
\hline $\begin{array}{l}\text { keamanan di lingkungan kampus pada } \\
\text { malam hari terjaga dengan baik }\end{array}$ & X.4.5 \\
\hline $\begin{array}{l}\text { Kendaraan di tempat parkir terjaga } \\
\text { keamanannya dengan baik }\end{array}$ & $X .4 .6$ \\
\hline $\begin{array}{l}\text { Keberadaan satpam di lingkungan } \\
\text { kampus memberikan rasa aman }\end{array}$ & X.4.7 \\
\hline $\begin{array}{l}\text { Staff atau tenaga kependidikan ramah } \\
\text { dalam memberikan pelayanan kepada } \\
\text { mahasiswa }\end{array}$ & $X .4 .8$ \\
\hline
\end{tabular}

Tabel 7. Indikator dimensi Empathy

\begin{tabular}{|l|c|}
\hline \multicolumn{1}{|c|}{ Indikator } & Kode \\
\hline $\begin{array}{l}\text { Komunikasi antara dosen dengan } \\
\text { mahasiswa terjaga dengan baik }\end{array}$ & $X .5 .1$ \\
\hline $\begin{array}{l}\text { Komunikasi antara pegawai atau tenaga } \\
\text { kependidikan dengan mahasiswa terjaga } \\
\text { dengan baik }\end{array}$ & $X .5 .2$ \\
\hline $\begin{array}{l}\text { Kemudahan dalam menghubungi dosen } \\
\text { untuk bimbingan }\end{array}$ & $\times .5 .3$ \\
\hline $\begin{array}{l}\text { Kesediaan tenaga kependidikan dalam } \\
\text { membantu mahasiswa menyelesaikan } \\
\text { permasalahan }\end{array}$ & $X .5 .4$ \\
\hline $\begin{array}{l}\text { Jam layanan akademik sesuai dengan } \\
\text { kebutuhan mahasiswa }\end{array}$ & $\times .5 .5$ \\
\hline
\end{tabular}

Tabel 8, 9, dan 10 berikut ini memperlihatkan indikator dan kode indikator untuk variabel reputasi, budaya organisasi, dan kepuasan mahasiswa.
Tabel 8. Indikator variabel Reputasi

\begin{tabular}{|l|c|}
\hline \multicolumn{1}{|c|}{ Indikator } & Kode \\
\hline $\begin{array}{l}\text { UNAND termasuk diantara universitas } \\
\text { ternama di Indonesia }\end{array}$ & $\mathrm{Y} .1$ \\
\hline $\begin{array}{l}\text { Gelar yang diperoleh dari UNAND dapat } \\
\text { diterima secara global }\end{array}$ & $\mathrm{Y} .2$ \\
\hline $\begin{array}{l}\text { Kurikulum yang digunakan UNAND } \\
\text { memenuhi permintaan lapangan kerja }\end{array}$ & $\mathrm{Y} .3$ \\
\hline $\begin{array}{l}\text { Lulusan UNAND mudah untuk } \\
\text { mendapatkan pekerjaan }\end{array}$ & $\mathrm{Y} .4$ \\
\hline $\begin{array}{l}\text { Mahasiswa UNAND memiliki } \\
\text { kemampuan yang lebih baik dari } \\
\text { mahasiswa universitas ternama lainnya }\end{array}$ & $\mathrm{Y} .5$ \\
\hline $\begin{array}{l}\text { UNAND sering mengadakan seminar } \\
\text { dengan pembicara dari tokoh publik }\end{array}$ & $\mathrm{Y} .6$ \\
\hline $\begin{array}{l}\text { Banyak beasiswa yang bisa didapatkan } \\
\text { oleh mahasiswa UNAND }\end{array}$ & $\mathrm{Y} .7$ \\
\hline
\end{tabular}

Tabel 9. Indikator variabel Budaya Organisasi

\begin{tabular}{|l|c|}
\hline \multicolumn{1}{|c|}{ Indikator } & Kode \\
\hline $\begin{array}{l}\text { Pihak UNAND selalu memberikan solusi } \\
\text { permasalahan mahasiswa dengan tepat }\end{array}$ & Z.1 \\
\hline $\begin{array}{l}\text { Pihak UNAND selalu menghargai setiap } \\
\text { mahasiswa yang mengemukakan ide } \\
\text { atau pendapatnya }\end{array}$ & $\mathrm{Z} .2$ \\
\hline $\begin{array}{l}\text { Pihak UNAND selalu berusaha untuk } \\
\text { mengurangi ketidakpuasan mahasiswa }\end{array}$ & $\mathrm{Z} .3$ \\
\hline $\begin{array}{l}\text { UNAND selalu mengutamakan Moral } \\
\text { kepada mahasiswanya }\end{array}$ & $\mathrm{Z.4}$ \\
\hline $\begin{array}{l}\text { UNAND Menerapkan kerja sama tim } \\
\text { daripada individu kepada mahasiswanya }\end{array}$ & $\mathrm{Z} .5$ \\
\hline $\begin{array}{l}\text { UNAND selalu memprioritaskan } \\
\text { kepentingan dan kebutuhan mahasiswa } \\
\text { agar kepuasan mahasiswa terpenuhi }\end{array}$ & $\mathrm{Z.6}$ \\
\hline $\begin{array}{l}\text { Aturan yang telah diterapkan UNAND } \\
\text { telah dipatuhi dengan baik oleh } \\
\text { mahasiswa }\end{array}$ & $\mathrm{Z.7}$ \\
\hline
\end{tabular}

Tabel 10. Indikator variabel Kepuasan Mahasiswa

\begin{tabular}{|l|c|}
\hline \multicolumn{1}{|c|}{ Indikator } & Kode \\
\hline $\begin{array}{l}\text { Kelengkapan fasilitas yang diberikan } \\
\text { pihak UNAND sesuai dengan harapan } \\
\text { saya }\end{array}$ & $\mathrm{A} .1$ \\
\hline $\begin{array}{l}\text { Kebersihan fasilitas yang ada di } \\
\text { lingkungan UNAND sesuai dengan } \\
\text { harapan saya }\end{array}$ & $\mathrm{A} .2$ \\
\hline $\begin{array}{l}\text { Keamanan di lingkungan kampus telah } \\
\text { sesuai dengan harapan saya }\end{array}$ & $\mathrm{A} .3$ \\
\hline $\begin{array}{l}\text { Pelayanan administrasi sesuai dengan } \\
\text { ekspektasi saya }\end{array}$ & $\mathrm{A} .4$ \\
\hline $\begin{array}{l}\text { Dosen mampu menyampaikan materi } \\
\text { dengan baik dan sesuai dengan } \\
\text { ekspektasi saya }\end{array}$ & $\mathrm{A} .5$ \\
\hline $\begin{array}{l}\text { Kondisi lingkungan dan suasana belajar } \\
\text { UNAND sesuai harapan saya }\end{array}$ & $\mathrm{A} .6$ \\
\hline $\begin{array}{l}\text { Saya merasa nyaman belajar di kampus } \\
\text { ini }\end{array}$ & $\mathrm{A} .7$ \\
\hline $\begin{array}{l}\text { Saya merasa puas dengan reputasi } \\
\text { kampus ini }\end{array}$ & $\mathrm{A} .8$ \\
\hline
\end{tabular}




\section{Hasil dan Pembahasan}

\section{Uji Outer Model}

Uji outer model terdiri dari dua pengujian yaitu uji validitas dan uji reliabilitas.

\section{Uji Validitas}

Uji validitas dilakukan dengan tujuan untuk menentukan apakah pertanyaan pada kuesioner penelitian telah valid atau tidak. Convergent validity dan discriminant validity digunakan untuk menentukan validitas instrument penelitian ini. Convergent validity dapat ditentukan berdasarkan nilai outer loading pada output PLS. Apabila nilai outer loading lebih besar atau sama dengan 0,6, maka indicator dikatakan valid. Terdapat 42 indikator yang dieliminasi karena memiliki nilai outer loading di bawah 0.6 , sehingga didapatkan model dengan indikator yang telah valid.

Selain nilai outer loading, nilai Average Variance Extracted (AVE) juga dapat digunakan untuk menilai convergent validity. Nilai AVE dikatakan valid apabila setiap variabel memiliki nilai sama atau lebih besar dari 0,5. Tabel 11 menunjukkan nilai AVE dari masing-masing variabel. Nilai AVE semua variabel berada di atas 0,5 di mana hal ini menandakan bahwa variabel kualitas pelayanan, budaya organisasi, reputasi, dan kepuasan mahasiswa dianggap telah memenuhi nilai untuk dikatakan valid.

Tabel 11. Nilai AVE

\begin{tabular}{|l|c|c|}
\hline \multicolumn{1}{|c|}{ Variabel } & AVE & Keterangan \\
\hline Kualitas pelayanan & 0.504 & Valid \\
\hline Buadaya Organisasi & 0.56 & Valid \\
\hline Reputasi & 0.56 & Valid \\
\hline Kepuasaan Mahasiswa & 0.528 & Valid \\
\hline
\end{tabular}

Uji validitas tidak hanya dinilai berdasarkan nilai convergent validity, akan tetapi juga berdasarkan nilai discriminant validity. Nilai discriminant validity didapatkan dari output SmartPLS yang dapat dilihat pada Tabel 12 . Nilai setiap konstruk untuk kualitas layanan, budaya organisasi, reputasi, dan kepuasan mahasiswa secara berurutan adalah 0,683; 0,$748 ; 0,748$ dan 0,706 . Berdasarkan nilai tersebut, dapat dilihat bahwa nilai setiap variabel lebih tinggi dibandingkan dengan nilai korelasi antar variabel lainnya. Hal ini menunjukkan bahwa model ini telah memiliki discriminant validity yang baik.
Tabel 12. Discriminant validity

\begin{tabular}{|l|c|c|c|c|}
\hline & $\begin{array}{c}\text { Kualitas } \\
\text { layanan }\end{array}$ & $\begin{array}{c}\text { Budaya } \\
\text { organisasi }\end{array}$ & Reputasi & $\begin{array}{c}\text { Kepuasan } \\
\text { mahasiswa }\end{array}$ \\
\hline $\begin{array}{l}\text { Kualitas } \\
\text { layanan }\end{array}$ & 0,683 & & & \\
\hline $\begin{array}{l}\text { Budaya } \\
\text { organisasi }\end{array}$ & 0,673 & 0,748 & & \\
\hline Reputasi & 0,495 & 0,524 & 0,748 & \\
\hline $\begin{array}{l}\text { Kepuasan } \\
\text { mahasiswa }\end{array}$ & 0,700 & 0,660 & 0,613 & 0,706 \\
\hline
\end{tabular}

\section{Uji Reliabilitas}

Uji reliabilitas memiliki tujuan untuk mengukur konsistensi dari suatu instrumen dalam mengukur suatu variabel. Nilai composite reliability dan cronbach alpha dapat digunakan untuk menguji reliabilitas instrument penelitian. Apabila nilai composite reliability dan nilai cronbach alpha berada di atas 0.7, maka instrument penelitian dan indicator-indikatornya dianggap reliabel. Tabel 13 menunjukkan nilai composite reliability dan cronbach alpha untuk setiap variabel dan terlihat bahwa kedua nilai tersebut telah berada di atas 0,7. Dengan demikian dapat disimpulkan bahwa variabelvariabel penelitian ini reliabel.

Tabel 13. Composite reliability dan cronbach alpha

\begin{tabular}{|l|c|c|}
\hline \multicolumn{1}{|c|}{ Variabel } & $\begin{array}{c}\text { Cronbach's } \\
\text { Alpha }\end{array}$ & $\begin{array}{c}\text { Composite } \\
\text { Reliability }\end{array}$ \\
\hline Budaya & 0.867 & 0.898 \\
\hline Kepuasan Mahasiswa & 0.855 & 0.887 \\
\hline Kualitas layanan & 0.932 & 0.940 \\
\hline Reputasi & 0.869 & 0.899 \\
\hline
\end{tabular}

\section{Uji Inner Model}

Nilai $\mathrm{R}$ square yang didapat dari output SmartPLS digunakan untuk menguji inner model. Tabel 14 memperlihatkan nilai $\mathrm{R}$ square kepuasan mahasiswa yaitu sebesar 0,628 . Oleh karena itu dapat dikatakan bahwa kualitas layanan, reputasi, dan budaya organisasi mempengaruhi kepuasan mahasiswa sebesar $62,8 \%$ dan sisanya dipengaruhi oleh variabel lain di luar bahasan pada penelitian ini.

Tabel 14. Nilai R-Square

\begin{tabular}{|c|c|}
\hline Variabel & $\boldsymbol{R}$ Square \\
\hline Kepuasan Mahasiswa & 0.628 \\
\hline
\end{tabular}

Uji inner model juga dapat dilakukan berdasarkan path coefficient value yang menunjukkan pengaruh positif atau negatif hubungan variabel independen terhadap variabel dependen. Tabel 15 menunjukkan path coefficient value. Nilai dari tabel menunjukkan 
bahwa variabel budaya organisasi, kualitas layanan dan reputasi memiliki hubungan positif terhadap variabel kepuasan mahasiswa.

Tabel 15. Path coefficient value

\begin{tabular}{|l|c|}
\hline \multicolumn{1}{|c|}{ Path } & $\begin{array}{c}\text { Path } \\
\text { coefficient }\end{array}$ \\
\hline $\begin{array}{l}\text { Budaya Organisasi } \rightarrow \text { Kepuasan } \\
\text { Mahasiswa }\end{array}$ & 0.228 \\
\hline $\begin{array}{l}\text { Kualitas layanan } \rightarrow \text { Kepuasan } \\
\text { Mahasiswa }\end{array}$ & 0.396 \\
\hline $\begin{array}{l}\text { Reputasi } \rightarrow \text { Kepuasan } \\
\text { Mahasiswa }\end{array}$ & 0.287 \\
\hline
\end{tabular}

\section{Uji Hipotesis}

Berdasarkan nilai $P$-value pada Tabel 16 dapat disimpulkan bahwa hipotesis satu, dua dan tiga dapat diterima. Namun hipotesis empat dan lima ditolak karena nilai $P$-value lebih besar dari 0.05. Penelitian ini menggunakan tingkat kepercayaan $95 \%$ sehingga nilai $T$-table adalah 1.96. Variabel berpengaruh signifikan jika nilai $T$-statistic diatas nilai $T$-table. Hubungan antara budaya organisasi, kualitas layanan dan kepuasan mahasiswa yaitu berpengaruh signifikan karena memiliki nilai $T$-statistic lebih besar daripada T-table. Sedangkan untuk nilai $T$-statistic budaya organisasi dan reputasi sebagai moderasi antara kualitas layanan dan kepuasan mahasiswa lebih kecil dibandingkan $T$-table sehingga dianggap pengaruhnya tidak signifikan.

Tabel 16. Nilai P-value dan T-statistic

\begin{tabular}{|l|c|c|l|}
\hline \multicolumn{1}{|c|}{ Hipotesis } & $\begin{array}{c}\text { T- } \\
\text { statistics }\end{array}$ & $\begin{array}{c}\text { P- } \\
\text { values }\end{array}$ & Hasil \\
\hline $\begin{array}{l}\text { Kualitas layanan } \rightarrow \\
\text { Kepuasan Mahasiswa }\end{array}$ & 7,386 & 0,00 & Diterima \\
\hline $\begin{array}{l}\text { Budaya } \rightarrow \text { Kepuasan } \\
\text { Mahasiswa }\end{array}$ & 4,262 & 0,00 & Diterima \\
\hline $\begin{array}{l}\text { Reputasi } \rightarrow \text { Kepuasan } \\
\text { Mahasiswa }\end{array}$ & 7,308 & 0,00 & Diterima \\
\hline $\begin{array}{l}\text { Moderating Effect } 1 \rightarrow \\
\text { Kepuasan Mahasiswa }\end{array}$ & 0,168 & 0,866 & Ditolak \\
\hline $\begin{array}{l}\text { Moderating Effect 2 } \rightarrow \\
\text { Kepuasan Mahasiswa }\end{array}$ & 0,743 & 0,458 & Ditolak \\
\hline
\end{tabular}

Hipotesis pertama menyatakan bahwa kualitas layanan berpengaruh signifikan terhadap kepuasan mahasiswa. Nilai $T$-statistic variabel kualitas layanan terhadap kepuasan mahasiswa lebih besar dari $T$-table yaitu sebesar 7,386, sehingga dapat ditarik kesimpulan bahwa hipotesis pertama diterima. Berdasarkan hasil tersebut dapat diartikan bahwa dengan memperbaiki dan meningkatkan kualitas layanan Universitas Andalas dari segi lima aspek yaitu tangible, reliability, assurance, responsiveness, dan empathy akan meningkatkan kepuasan mahasiswanya. Hal ini sesuai dengan penelitian sebelumnya yaitu Saleem et al. (2017), Budiarti (2018), Chandra et al. (2018) dan ljaz et al. (2011).

Nilai $T$-statistic yang didapatkan untuk hipotesis kedua adalah sebesar 4,262, dimana nilai tersebut lebih besar daripada nilai $T$-table. Hal ini menunjukkan bahwa budaya organisasi berpengaruh signifikan terhadap kepuasan mahasiswa dengan kata lain hipotesis kedua diterima. Berdasarkan hal ini dapat diartikan bahwa dengan semakin baiknya budaya organisasi Universitas Andalas akan meningkatkan kepuasan mahasiswanya. Budaya organisasi yang dimaksud seperti mengutamakan moral, kerja sama tim, memberikan solusi yang tepat, menghargai pendapat dan ide mahasiswa dan lainnya. Hal ini sesuai Saleem et al. (2017) dan Triwardhani \& Handayani (2013), namun berbeda dengan Budiarti (2018), hal ini bisa disebabkan oleh penggunaan indikator yang berbeda, karena pada penelitian ini indikator budaya organisasi diambil dari dua jurnal yang berbeda. Selain itu perbedaan karakteristik sampel juga dapat menyebabkan perbedaan pada hasil penelitian.

Nilai $T$-statistic yang didapatkan untuk hipotesis ketiga sebesar 7,308. Nilai $T$-statistic tersebut lebih besar dibandingkan nilai $T$-table. Berdasarkan nilai ini dapat ditarik kesimpulan bahwa reputasi memiliki hubungan yang signifikan terhadap kepuasan mahasiswa atau dengan kata lain hipotesis ketiga diterima. Reputasi yang dimaksud seperti gelar yang dapat diterima secara global, lulusan yang mudah untuk mendapatkan pekerjaan, dan lainnya. Hal ini sesuai dengan penelitian Saleem et al. (2017) dan Wibowo (2009).

Nilai $T$-statistic yang diperoleh berdasarkan pengolahan data untuk hipotesis keempat sebesar 0,168 , dimana nilai tersebut lebih kecil daripada nilai T-table. Berdasarkan nilai tersebut dapat disimpulkan bahwa budaya organisasi tidak berpengaruh signifikan sebagai moderasi antara kualitas layanan dan kepuasan mahasiswa atau dengan kata lain hipotesis keempat ditolak. Hasil penelitian ini sesuai dengan Budiarti (2018) namun berbeda dengan Saleem et al. (2017). Hipotesis ini ditolak dikarenakan indikator pada penelitian ini diambil tidak dari satu jurnal, akan tetapi dari beberapa 
jurnal sehingga dapat menyebabkan perbedaan hasil penelitian dengan penelitian sebelumnya. Budaya organisasi pada penelitian ini terdiri dari indikator penilaian seperti moral, kerja sama tim, aturan yang diterapkan dan lain-lain, dimana hal tersebut dapat dikatakan belum terlalu dirasakan oleh mahasiswa UNAND. Sehingga berdasarkan penelitian dapat disimpulkan bahwa budaya organisasi tidak memiliki efek moderasi atau tidak memperkuat atau memperlemah antara kualitas layanan terhadap kepuasan mahasiswa

NilaiT-statistic untuk hipotesis kelima didapatkan sebesar 0,743 , dimana nilai tersebut lebih kecil daripada $T$-table. Berdasarkan hasil tersebut dapat disimpulkan bahwa reputasi tidak berpengaruh secara signifikan sebagai moderasi antara kualitas layanan terhadap kepuasan mahasiswa atau dengan kata lain hipotesis kelima ditolak. Penelitian ini sejalan dengan Tjahyadi et al. (2018) namun terdapat perbedaan antara Saleem et al. (2017) dan Budiarti (2018). Perbedaan hasil ini bisa disebabkan oleh perbedaan indikator yang digunakan, dalam penelitian ini indikator reputasi diambil dari tiga jurnal, sehingga dapat menyebabkan perbedaan hasil dengan penelitian sebelumnya. Selain itu, reputasi universitas tidak terlalu berkaitan terhadap kualitas layanan, akan tetapi lebih berkaitan dengan hal yang dipandang mahasiswa atau masyarakat seperti menjadi universitas yang terkenal di Indonesia, mudahnya lulusan mendapatkan pekerjaan, banyaknya beasiswa yang bisa diperoleh di universitas tersebut dan lain-lain. Hal-hal tersebut tidak berkaitan secara langsung terhadap kualitas layanan, sehingga dapat dikatakan reputasi tidak memperkuat atau memperlemah hubungan antara kualitas layanan dan kepuasan mahasiswa.

\section{Kesimpulan}

Hasil penelitian menunjukkan bahwa variabel kualitas pelayanan, budaya organisasi, dan reputasi berpengaruh signifikan terhadap kepuasan mahasiswa Universitas Andalas. Artinya, dengan melakukan perbaikan atau peningkatan terhadap variabel-variabel tersebut dapat mempengaruhi tingkat kepuasan mahasiswa secara signifikan.

Variabel budaya organisasi dan reputasi juga di uji sebagai variabel moderasi antara kualitas layanan terhadap kepuasan mahasiswa. Hasil yang diperoleh yaitu variabel budaya organisasi dan reputasi tidak berpengaruh signifikan sebagai variabel moderasi antara kualitas layanan terhadap kepuasan mahasiswa. Artinya variabel budaya organisasi dan reputasi tidak memperkuat atau memperlemah hubungan antara kualitas layanan terhadap kepuasan mahasiswa.

\section{Daftar Pustaka}

Al-Otaib, S. A., Yusof, S. M., \& Wanlsmail, W. K. (2019, January). The Influence of Organizational Culture on Students' Satisfaction in Saudi Arabia. In Proceedings of the International Conference on Industrial Engineering and Operations Management Bang, 7(March 5).

Alghamdi, F. (2018). Total Quality Management and Organizational Performance: A Possible Role of Organizational Culture. International Journal of Business Administration, 9(4), 186-200.

Apriyani, D. A. dan Sunarti, S. (2017). Pengaruh Kualitas layanan Terhadap Kepuasan Konsumen (Survei Pada Konsumen The Little A Coffee Shop Sidoarjo). Jurnal Administrasi Bisnis, 51(2), 1-7.

Aryska, M., \& Kasmirudin, K. (2017). Pengaruh Reputasi Perusahaan dan Kualitas Pelayanan Terhadap Kepuasan Pasien (Kasus Rumah Sakit Islam Ibnu Sina Pekanbaru) (Disertasi, Riau University).

Budiarti, E. M. (2018). Pengaruh Kualitas Layanan, Budaya Akademik, dan Citra Lembaga terhadap Kepuasan Mahasiswa. JMSP (Jurnal Manajemen dan Supervisi Pendidikan), 2(3), 169-178.

Chandra, T., Ng, M., Chandra, S., \& Priyono (2018). The Effect of Service Quality on Student Satisfaction and Student Loyalty: An Empirical Study. Journal of Social Studies Education Research, 9(3), 109-131.

Ghozali, I. (2014). SEM Metode Alternatif dengan menggunakan Partial Least Squares (PLS). Semarang: Badan Penerbit Universitas Diponegoro.

Ijaz, A., Irfan, S. M., Shahbaz, S., Awan, M., \& Sabir, M. (2011). An empirical model of student satisfaction: Case of Pakistani public sector business schools. Journal of quality and Technology Management, 7(2), 91-114. Jancikova, A., \& Brychta, K. (2009). TQM and organizational culture as significant factors 
in ensuring competitive advantage: A theoretical perspective. Economics \& Sociology, 2(1), 80-95.

Kamal, R. F. (2016). Evaluasi Kualitas layanan Program Studi S-1 Di Universitas Andalas. (Skripsi, Universitas Andalas Padang).

Khattab, F. (2018). Developing a service quality model for private higher education institutions in Lebanon. J. Mgt. Mkt. Review, 3(1), 24-33.

Kitchroen, K. (2004). Literature Review: Service Quality in Educational Institutions. ABAC Journal, 24(2), 14-25.

Martasubrata, N., \& Suwatno, S. (2016). Mutu layanan akademik sebagai determinan kepuasan mahasiswa. Jurnal Pendidikan Manajemen Perkantoran (JPManper), 1(1), 136-143.

Rinala, I. N., Yudana, I. M., \& Natajaya, I. N. (2013). Pengaruh kualitas pelayanan akademik terhadap kepuasan dan loyalitas mahasiswa pada Sekolah Tinggi Pariwisata Nusa Dua Bali. Jurnal Administrasi Pendidikan Indonesia, 4(1).

Saadi, I. (2017). The Role of Organizational Culture in Adopting Total Quality Management: Case Study the Salt Complex, El Outaya, Biskra State. Management Studies and Economic Systems, 54(5805), 1-18.

Safitri, A. H. (2015). Analisis Pengaruh Kualitas layanan Di Perguruan Tinggi Terhadap Kepuasan Dan Loyalitas Mahasiswa (Studi Kasus: Fakultas Teknik Universitas Andalas Padang). (Skripsi, Universitas Andalas Padang).

Saleem, S. S., Moosa, K., Imam, A., \& Khan, R. A. (2017). Service quality and student satisfaction: the moderating role of university culture, reputation and price in education sector of Pakistan. Iranian Journal of Management Studies (IJMS) http://ijms. ut. ac. ir, 10(1), 237-258.

Satriyanti, E. O. (2012). Pengaruh Kualitas Layanan, Kepuasan Nasabah dan Citra Bank terhadap Loyalitas Nasabah Bank Muamalat di Surabaya. Journal of Business and Banking, 2(2), 171-184.

Tjahyadi, R. A., Lu, C., \& Fionita, J. (2018). HIEDQUAL (High Education Quality) Dan Kepuasan Mahasiswa: Peran Reputasi Universitas Sebagai Variabel Mediasi. Jurnal Manajemen dan Bisnis Indonesia, 5(3), 315-326.

Uluputty, N. F. (2019). Pengaruh Kualitas Pelayanan, Budaya Akademik dan Kinerja Dosen terhadap Kepuasan Mahasiswa. POINT, 1(2), 22-30.

Wibowo, A. I. (2009). Pengaruh Kualitas Layanan, Reputasi, dan Nilai Layanan Perguruan Tinngi terhadap Kepuasaan Mahasiswa. Bina Ekonomi, 13(2), 59-74.

Widodo, H. (2016). Potret pendidikan di Indonesia dan kesiapannya dalam menghadapi masyarakat ekonomi Asia (MEA). Cendekia: Jurnal Kependidikan Dan Kemasyarakatan, 13(2), 293-308.

Ximenes, N. A. B. (2017). Pengaruh Kualitas layanan Terhadap Kepuasan Dan Loyalitas Mahasiswa Pada Institute Of Business (lob) Di Timor-Leste. E-Jurnal Ekonomi dan Bisnis Universitas Udayana, 6(8), 29172954.

Yuliana, R. (2012). Analisis Pengaruh Strategi Service Recovery Yang Dilakukan Perbankan Terhadap Kepuasan Nasabah Di Kota Semarang. JURNAL STIE SEMARANG (Edisi Elektronik), 4(2), 39-52. 